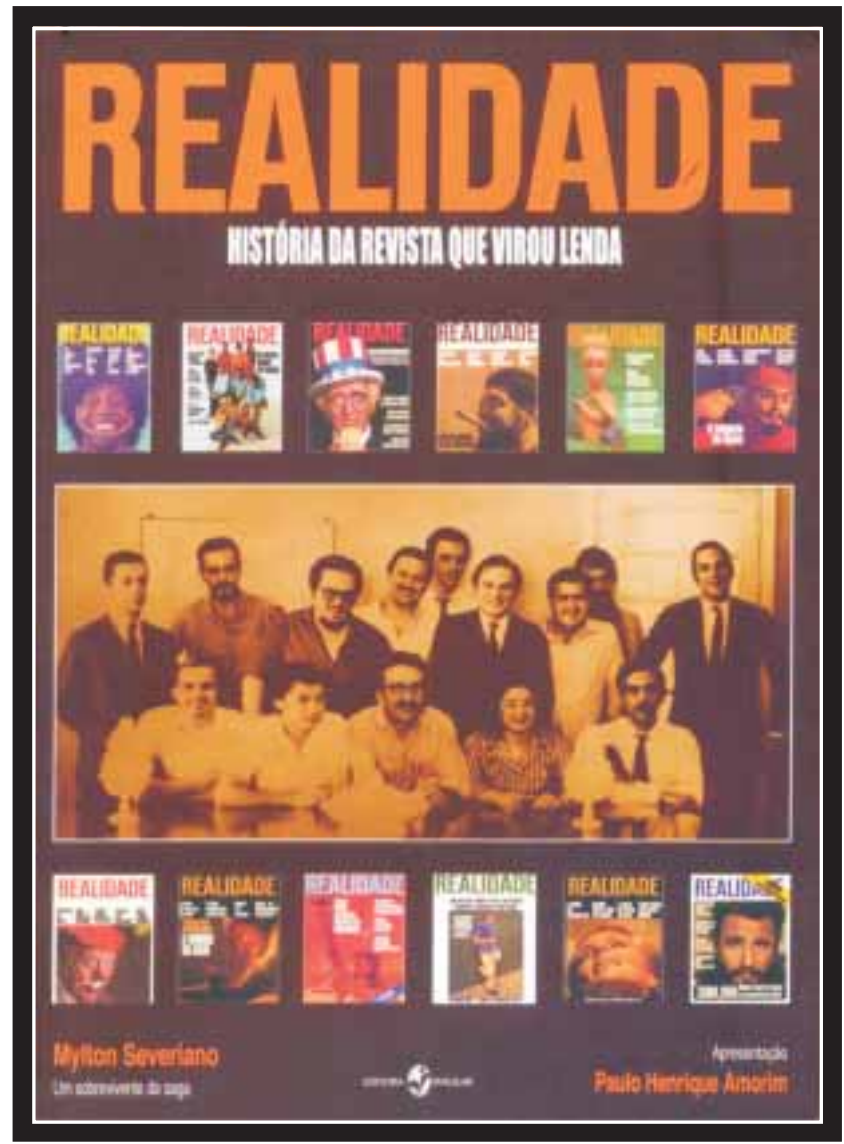

SILVA, Mylton Severiano da. Realidade - História da revista que virou lenda. Florianópolis: Editora Insular, 2013. 320 p. 


\section{Não é lenda; é Realidade}

It's not legend; it's Reality

Joaquim Francisco Gonçalves de Brito Amaro*

A revista Realidade, que circulou de 1966 a 1976, publicada pela Editora Abril, é constantemente lembrada nos cursos de Jornalismo, quando o assunto é a grande reportagem. E também nos programas de pós-graduação em Comunicação: já se produziram dissertações e teses discutindo as razões profundas e o significado que teve para o próprio jornalismo e para a cultura brasileira a revista mensal de reportagens cujo sucesso foi instantâneo, comprovado por seguidos e expressivos aumentos de tiragem, até o limite de aproximadamente 500.000 exemplares - número que seria espantoso mesmo hoje, quanto mais no Brasil de 50 anos atrás, para uma revista com essa receita e periodicidade, diferente de tudo o que existia no mercado editorial. Repórteres, fotógrafos, redatores, planejadores gráficos, diagramadores que fizeram Realidade já deram inúmeros depoimentos e entrevistas sobre o trabalho que realizaram lá, sempre desafiados a revelar "o segredo" daquele projeto.

Mylton Severiano da Silva, o Myltainho, apelido que ganhou numa redação no início da carreira, foi um dos profissionais que fundaram, com Realidade, uma escola sem precedentes na história das revistas brasileiras - escola de reportagem, de fotografia, de texto, de edição, de apresentação visual. Severiano trabalhou lá como editor de texto, arte e ofício no qual se tornaria um grande mestre. Sempre acolheu quem quisesse saber de sua experiência em Realidade: só de entrevistas por escrito, concedeu 35 no período entre 2003 e 2010, todas mantidas arquivadas. E ainda teve a generosidade de escrever

*'Graduado em Comunicação Social - habilitação Jornalismo pela Universidade Estadual de Londrina e mestrando em Comunicação pela Universidade Estadual de Londrina. 
as 320 páginas de Realidade - História da revista que virou lenda (Editora Insular, 2013), livro que representa uma de suas últimas e mais significativas contribuições para a história do jornalismo brasileiro ${ }^{1}$.

Pesquisadores em geral encontram, no livro de Myltainho, nada menos que o projeto, até então inédito, com a receita editorial da revista e as diretrizes para a sua produção, escrito por seu criador e redatorchefe dos primeiros anos, Paulo Patarra, falecido em 2008. Escrito e comentado - isto é, Patarra ia anotando e guardando observações, impressões e aprendizados a respeito de cada edição, como quem faz um diário. É, talvez, o mais próximo que se pode chegar do "segredo" da receita de Realidade. Material de grande riqueza para jornalistas, em particular.

Paulo Patarra já estava na Editora Abril quando surgiu a oportunidade de fazer uma revista como viria a ser Realidade; era diretor de Quatro Rodas, à época também recente e inovadora. O projeto não antecedeu a revista, nasceu junto. Patarra teorizava a prática enquanto se faziam números zeros. Traçou um perfil do leitor a ser alcançado, estabeleceu diretrizes para conquistá-lo, disse como deviam ser feitas e apresentadas as reportagens. Queria o que não existia. "O inusitado, o violento, o estranho, o impossível, o movimento e o belo são os assuntos de capa", escreveu, segundo Myltainho (p.77).

Também foi Patarra o responsável pela formação da equipe que iniciou a revista. Em dezembro de 2007, um mês antes de sua morte, Severiano recebeu dele, por meio de Sérgio de Souza, uma caixa com meio milheiro de laudas do diário relativo às 16 primeiras edições. E ainda fotos, bilhetes, comunicados e outros documentos que permitem conhecer os bastidores da produção da revista e, em parte, as difíceis relações da Editora Abril com o governo militar por causa da linha de Realidade dificuldades crescentes que culminaram com o afastamento de Patarra de seu posto, em 1968, após a publicação de 32 números, pouco antes da

O jornalista Mylton Severiano da Silva morreu no dia 9 de maio de 2014, aos 73 anos, de infarto, em Florianópolis (SC), onde morava. 
decretação do Ato Institucional ${ }^{\circ} 5$, com o qual foi drasticamente reduzida a liberdade política no país e se institucionalizou uma severa censura à imprensa.

É nessa primeira fase de Realidade que Myltainho se detém. Ela é que foi "verdadeiramente gloriosa, [...] resultado da conjugação de muitos talentos e uma enorme energia", conforme as palavras insuspeitas de Roberto Civita ${ }^{2}$, filho do fundador da Editora Abril, Victor Civita, e diretor da revista. Para Myltainho, tratou-se de "uma saga". Na capa do livro, o autor se autointitula "um sobrevivente da saga". E aparece na foto que ilustra a capa, tirada numa reunião para discutir rumos logo após o afastamento de Paulo Patarra, ao lado de outros 13 participantes dos primeiros tempos de Realidade. Eles se dispersariam. Aos oito que já haviam morrido quando o livro foi lançado - inclusive o fotógrafo Luigi Mamprin - somou-se agora o próprio autor.

$\mathrm{O}$ texto se revela uma homenagem, em forma de reportagem acrescida de testemunho pessoal, àquele grupo de pioneiros, e outros mais, que fizeram história no jornalismo brasileiro. Severiano saiu a campo para reencontrar e colher depoimentos de companheiros de saga, e ainda transmitiu suas próprias impressões sobre pessoas ou fatos. Somados esses elementos às informações sobre as reflexões prévias e o projeto editorial escritos por Paulo Patarra, o resultado é um livro escrito com tal habilidade que pode ser lido como se estivéssemos diante de um romance.

Nesse romance, a parte mais interessante da aventura está reservada para o trabalho do repórter e do fotógrafo. Não que ela ocupe

\footnotetext{
A edição 2324 da Revista Veja, de 5 de junho de 2013, transcreve memórias deixadas por Roberto Civita, que havia morrido no dia 26 de maio. No trecho sobre a revista Realidade (p.99), Civita fala das razões que levaram a Editora Abril a produzir uma revista com aquela qualidade, num curioso tom em que, ao mesmo tempo, se desculpa por ter reunido equipe tão competente, mas com posições ideológicas muito diferentes das dele. Suas palavras: "Na fase inicial, a verdadeiramente gloriosa, ela [Realidade] foi o resultado da conjugação de muitos talentos e uma enorme energia. Eram pessoas com visões de mundo diferentes. Havia uma preponderância da esquerda, dentro da redação, e alguns jornalistas da equipe chegaram a ter militância política clandestina, com vida dupla, naqueles chamados anos de chumbo. Sinceramente, eu não percebi. Só me dei conta mais tarde. [...] Minha visão sempre foi liberal em relação aos costumes, mas no plano político e econômico já estava convencido de que a livre-iniciativa é o único caminho para o progresso e o desenvolvimento. [...] Minha visão do mundo, naquele momento, se encontrou com a de vários jornalistas da redação e houve, de certo modo, uma convergência. [...] Daquela convergência nasceu a REALIDADE”.
} 
a maior parte da narrativa, mas, quando surge, revela-se em toda a sua originalidade.

Em Realidade, a fotografia surgia não como mera ilustração do texto, mas como um trabalho autoral que podia trazer informações, por si sós, complementares ao texto, quase com vida independente - ainda que, necessariamente, harmônica e formando um conjunto 3 .

A força da fotografia na receita da revista se fez sentir em momentos graves da vida de Realidade, como num episódio narrado por Severiano, que marca a estreia da fotógrafa Claudia Andujar.

Para uma reportagem sobre a decadência da tradição do trabalho das parteiras, publicada em janeiro de 1967, Claudia havia fotografado, de frente, uma criança saindo da mãe, com a cabeça apoiada na mão da parteira. Havia outras fotos, de outros momentos. O título já estava escolhido: Nasceu! Deu-se, então, "uma das mais incríveis sessões de discussão política e exercício de autocensura de que participei”, afirma Myltainho (p.107). Por uma tarde inteira, a equipe, inclusive com a presença do diretor Roberto Civita, discutiu se a foto de abertura da matéria - a ser publicada numa página dupla - devia ser a da criança saindo da mãe ou outra, já nas mãos da parteira. Venceram os defensores da foto mais branda, mas a publicação da primeira, mesmo de forma mais discreta, numa das páginas seguintes, causou protestos de representantes da Igreja e fez com que um juiz de Direito do Rio de Janeiro mandasse apreender nas bancas os exemplares da revista, acusada de pretender "despertar animalidade pura e simples" com cenas como aquela. Segundo Severiano, o prejuízo financeiro foi pequeno, porque a maior parte da tiragem já havia sido vendida.

Realidade - História da revista que virou lenda pode ser tomado como um manual de reportagem - de um tipo de reportagem, não necessariamente grande como aquelas publicadas na revista, que virtualmente desapareceu da imprensa. Mudaram os tempos? Mudaram

3 Um trabalho específico sobre a fotografia em Realidade, no qual se pode inclusive folhear, digitalmente, algumas das principais reportagens publicadas pela revista, foi realizado pela equipe do pesquisador Marcelo Eduardo Leite. Tem o título "O fotojornalismo (autoral) de uma revista" e pode ser acessado em realidade.ufca.edu.br. 
os jornalistas, ou os leitores, ou a educação, a cultura, a economia? Perguntas a responder. De qualquer forma, quando se retomar consciência daquilo que se perdeu, e voltar o tempo da reportagem que amplia horizontes, encanta, desvenda, humaniza e acrescenta, o livro do Myltainho será um ótimo ponto de partida para transformar ideias em Realidade. Com "R" maiúsculo. 